\title{
6. How to organize system operation and connection requirements?
}

\section{Leonardo Meeus with Valerie Reif}

In this chapter, we answer four questions. First, why pay attention to detailed technicalities? Second, how to organize regional system operation? Third, how to introduce minimum technical standards? Fourth, how to proceed with the implementation of technical standards?

\subsection{WHY PAY ATTENTION TO DETAILED TECHNICALITIES?}

In this section, we revisit two iconic incidents where technical requirements came to the attention of the wider public. They involve a solar eclipse and a cruise ship.

First, the solar eclipse. ${ }^{1}$ On 20 March 2015, a solar eclipse took place that affected Europe, starting at 08.01 in the western part of Portugal and ending at 11.58 in the eastern part of Romania. It was the first solar eclipse in a power system with significant amounts of solar power. Solar photovoltaic (PV) generation gradually reduces as the sun goes down in the evening and raises back up with the sunrise. For the solar eclipse the same would happen, but much faster. In anticipation of the event, regional groups of transmission system operators (TSOs) in European Network of Transmission System Operators for Electricity (ENTSO-E) had analysed the potential impact and had looked at countermeasures that could be useful during the eclipse.

In the Nordics, the TSOs had not expected to be significantly affected by the reduction in solar PV generation. The Nordic countries decided to limit exchanges with Continental Europe (CE). The idea was to protect the Nordic system from a possible blackout in CE and also to help CE recover from a blackout if this unlikely event were to occur.

Great Britain reported a combination of different effects during the solar eclipse. In comparison with a normal day, there was a demand suppression due to people stopping their activities to be able to watch the event. There was also a demand increase due to lighting that extended beyond the eclipse. There was a loss of wind generation in addition to the loss of PV generation because solar eclipses typically reduce wind speeds. The balancing in real time by the system operated mainly relied on pumped hydro storage.

In Continental Europe, the impact was expected to be the greatest. The installed solar PV capacity in the CE synchronous area in 2015 was estimated at around $89 \mathrm{GW}$. As a protection measure, some TSOs had increased their balancing reserves. The additional balancing costs during the event ranged from $€ 40000$ for France to $€ 3.6$ million for Germany. The Italian TSO Terna had proactively removed 4400 MW of planned solar PV production from the day-ahead market. TSOs had raised awareness and informed market players of the responsibilities they had during the eclipse. Extra training of control room operators had been organized. 
During the eclipse, some TSOs strategically used pumped hydro storage plants. Teleconferences among CE TSOs were held and continuous communication took place between control rooms in $\mathrm{CE}$ and the Nordics. Ex post analysis showed that the frequency quality during the event was high. In Continental Europe, the frequency never deviated more than $48 \mathrm{mHz}$ from the set point of $50 \mathrm{~Hz}$. In Great Britain, the frequency only briefly exceeded operational targets at the very beginning of the solar eclipse at 08.00.

Second, the cruise ship. ${ }^{2}$ The story starts with the Norwegian Pearl. This ship needed to pass beneath a high-voltage line in the north of Germany during the evening of 4 November 2006. For security reasons, the line was manually disconnected by the TSO responsible. What should have been a regular operational task that had been done several times during the previous years, on this day triggered the tripping of several high-voltage lines from the north to the south of Continental Europe within a number of seconds. Lines that disconnected included interconnection lines between the German TSOs E.ON Netz and RWE, internal E.ON Netz lines (DE), internal APG lines (AT), interconnection lines between HEP (HR) and MAVIR (HU), internal HEP lines (HR) and internal MAVIR lines (HU). Finally, the interconnection lines between Morocco and Spain also tripped due to low frequency. The final report by UCTE on the system disturbance concluded that the system was operated close to its security limits and coordination and communication among the TSOs had been insufficient.

During this incident, the CE grid was split into three areas. Each experienced significant power imbalances with a frequency drop in two of the areas and an increase in the third. The TSOs completed full re-synchronization of the CE system 38 minutes after the splitting and were able to re-establish a normal situation in all European countries in less than two hours. Figure 6.1 illustrates the frequency deviations in the three $\mathrm{CE}$ areas, and the tripping of generation and shedding of load that followed.

The western area was composed of Spain, Portugal, France, Italy, Belgium, Luxemburg, the Netherlands, a part of Germany, Switzerland, a part of Austria, Slovenia and a part of Croatia. This area was facing a significant imbalance due to missing imports from the east, which led to a quick drop in frequency down to about $49.0 \mathrm{~Hz}$. At this frequency, larger generator units synchronously connected to the transmission grid were expected to stay connected. In many

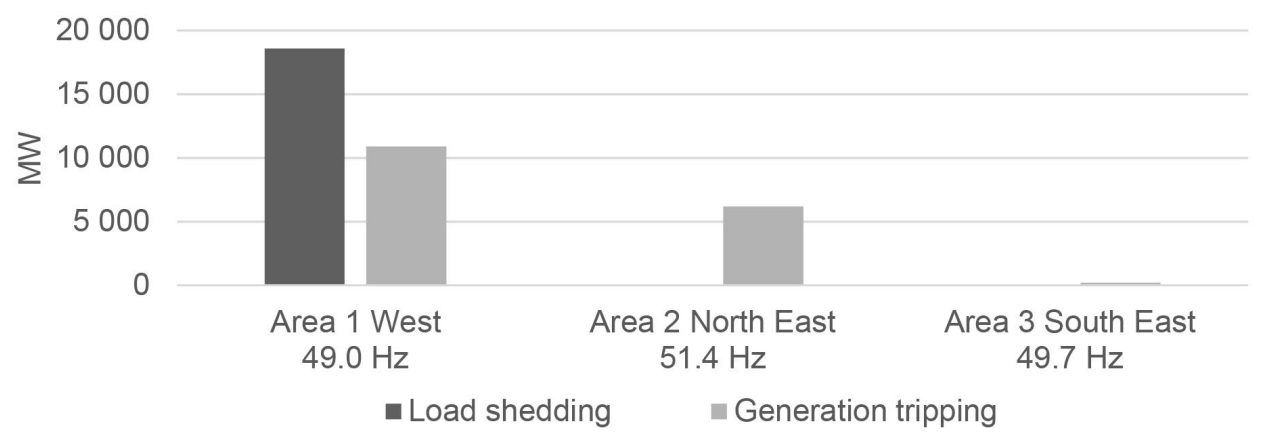

Source: Own illustration based on the UCTE (2007) report.

Figure 6.1 Capacities lost at the frequencies reached in the three areas during the split of the Continental European system on 4 November 2006 
countries, however, smaller generation units only connected to distribution grids had to be able to withstand a drop to $49.5 \mathrm{~Hz}$. In the western area, $10900 \mathrm{MW}$ of generation disconnected, mainly wind and combined heat and power (CHP) generation connected to the distribution grid. Except for one $700 \mathrm{MW}$ thermal generation unit in Spain, none of the generation that tripped was connected to the TSO networks. The load shedding that followed was aimed at solving the initial imbalance in the western area plus the increased imbalance from the generation that disconnected. In total, about $1600 \mathrm{MW}$ of pumps and $17000 \mathrm{MW}$ of consumption were shed.

The north-eastern area was composed of a part of Austria, the Czech Republic, a part of Germany, a part of Hungary, Poland, Slovakia and Ukraine. In this area, the frequency rose to $51.4 \mathrm{~Hz}$ due to a generation surplus of more than $10000 \mathrm{MW}$. Automatic predefined actions and automatic tripping of generation sensitive to high frequency values followed, mainly of wind power connected to the distribution grid, which reduced the frequency to $50.3 \mathrm{~Hz}$. The tripping of wind generation was estimated at around $6200 \mathrm{MW}$ and played a crucial role in decreasing the frequency during the first seconds of the disturbance.

The south-eastern area was composed of North Macedonia, Montenegro, a part of Croatia, Greece, Bosnia and Herzegovina, Serbia, Albania, a part of Hungary, Bulgaria and Romania. This area only faced a slight under-frequency due to a lack of power of around $770 \mathrm{MW}$, but no automatic actions or load shedding took place during the event.

The three main lessons learned can be summarized as follows. First, the cruise ship incident was a wake-up call that there are many smaller units, like wind power plants, CHP and PV, connected to the system that made the problem worse because they simply disconnected to protect their own equipment. These units also caused challenges during frequency restoration, as they automatically reconnected to the grid without any control by TSOs or DSOs when the voltage and frequency conditions were in the acceptable range. In the new decentralized system, it is not enough to manage the technical requirements of the larger units; the small ones also have a technical responsibility that needs to be defined more clearly. This responsibility cannot be limited to the national level because it will have consequences across borders. Second, an understanding emerged that system operation needs to be regionalized. The cruise ship incident was indeed the start of regional security coordination initiatives (RSCIs), which were introduced to avoid this happening again. By sharing information and having a centre that monitors different control areas, the national TSOs are better informed when taking action. Third, the preparation for the first eclipse in a power system with a significant amount of solar power worked out. Its ad hoc organization, however, triggered a debate on how such coordination can be improved in the future.

\subsection{HOW TO ORGANIZE REGIONAL SYSTEM OPERATION?}

In Chapter 3, we showed how regional system operation evolved from RSCIs to regional security coordinators (RSCs) to regional coordination centres (RCCs) following the cruise ship incident discussed here. In this section, we first discuss in more detail the tasks of these regional entities, which go beyond the capacity calculation task we focused on in Chapter 3. We then introduce the Risk Preparedness Regulation (EU) 2019/941, which is part of the Clean Energy Package (CEP) and was a response to the solar eclipse incident. 


\subsubsection{Regional System Operation Tasks}

Figure 6.2 shows how regional system operation tasks have evolved since voluntary initiatives were launched in 2008. The voluntary RSCIs offered regional coordination services and provided TSOs with an overview of electricity flows at the European regional level to complement the TSOs' own system data. The System Operation Guideline (SO GL) later formalized TSO coordination by setting out common requirements for the establishment of RSCs and for their tasks.

RSCs deliver five core operational services to support national TSO decision-making, namely coordinated capacity calculation, coordinated security analysis, delivery of the common grid model, outage planning coordination, and short- and medium-term adequacy. In addition, they are required to review the relevant TSO's system defence and restoration plans for consistency and to provide a technical report to all the TSOs involved, which in turn transmit it to the relevant regulatory authorities and to ENTSO-E to monitor implementation. RSCs also provide critical grid situation (CGS) support to TSOs, a responsibility that was introduced with the cold spell in winter 2017/2018. ${ }^{3}$ This includes support to identify the risk level at an early stage and to organize communication in advance and during the operational planning phase if a CGS is expected and appropriate remedial actions needing to be prepared. Furthermore, the SO GL defines certain annual reporting duties of RSCs to ENTSO-E.

The RCCs were created within the geographical scope of system operation regions (SORs), a new concept introduced in the CEP. A SOR spans several established concepts, including TSOs, bidding zones, bidding zone borders and capacity calculation regions. A SOR covers at least one capacity calculation region and the TSOs in a SOR are required to participate in that region's RCC. All TSOs of a SOR are required to forward a proposal for the establishment of RCCs to the relevant national regulatory authority (NRA) for approval by 5 July 2020. The proposal should include the Member State in which the RCC will be located, the TSOs participating, arrangements regarding the RCC's organization, financing, operations and liability together with an implementation plan for the RCC's entry into operation. Following approval by the NRAs, the RCCs will replace the RSCs and enter into operation by 1 July 2022.

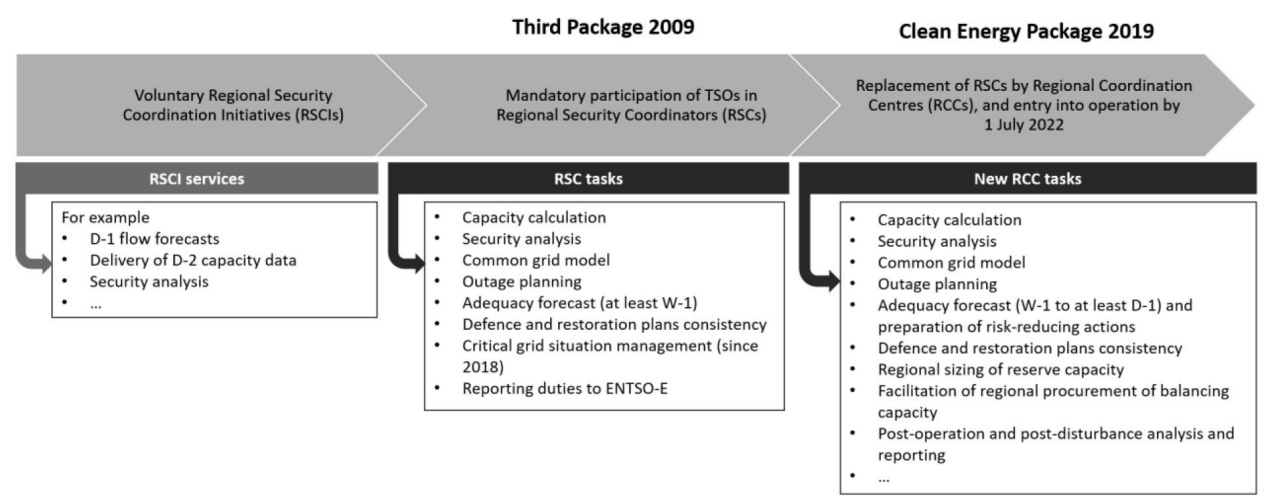

Figure 6.2 Evolution of RSCIs into RSCs and then RCCs and a selection of their tasks 
The five core operational services and the supporting tasks to ensure consistency of the TSOs' defence and restoration plans and manage CGSs will be transferred from the RSCs to the RCCs. In addition, the portfolio of RCC tasks will include new tasks listed in the CEP. In total, the CEP lists 16 tasks for RCCs. Some of the additional tasks are set by default, for example post-operation and post-disturbance analysis and reporting, regional sizing of reserve capacity and facilitation of regional procurement of balancing capacity. Other tasks to be performed by RCCs are subject to a request from TSOs - for example, support for coordination and optimization of regional restoration - or subject to delegation from ENTSO-E - for example, identification of regional electricity crisis scenarios or carrying out seasonal adequacy assessments. RCCs are to remain open to also extending their portfolio to potential future needs for TSO regional coordination.

RCCs issue coordinated actions (for capacity calculation and security analysis) and recommendations (for all other tasks) to the TSOs. The TSOs will implement coordinated actions except where this would result in the violation of security limits. In such cases, the TSO is required to file a report to the RCC and the other TSOs in the SOR. The RCC will assess the impact of the decision on the other TSOs in the SOR and may propose a different set of coordinated actions. If a TSO decides to deviate from a recommendation, it needs to submit a justification to the RCC and the other TSOs in the SOR. Note that under certain conditions the Member States in a SOR may jointly decide to grant their RCCs competence to issue coordinated actions for one or more tasks for which currently only recommendations are given.

\subsubsection{Risk Preparedness}

The Risk Preparedness Regulation (EU) 2019/941, which was adopted as part of the Clean Energy Package, sets out a common framework of rules on how to prevent, prepare for and manage electricity crises. It considers that a regional approach brings significant benefits in terms of the effectiveness of the measures implemented and the optimal use of resources, and so requires Member States to cooperate in the regional context. Regulation (EU) 2019/941 was inspired by the above solar eclipse incident.

As mentioned, RCCs are required to perform the tasks of regional relevance assigned to them in accordance with both the Risk Preparedness Regulation (EU) 2019/941 and the Electricity Regulation (EU) 2019/943. ENTSO-E can delegate to RCCs tasks relating to seasonal adequacy assessment and to the identification of regional electricity crisis scenarios. Note that delegated tasks are to be performed under the supervision of ENTSO-E. On the basis of these regional electricity crisis scenarios, Member States will establish and update their national electricity crisis scenarios, in principle every four years. These scenarios then provide the basis for the national risk-preparedness plans that each Member State is required to develop. In this regard, the geographical scope of SORs is relevant in the identification of regional electricity crisis scenarios and risk assessments.

\subsection{HOW TO INTRODUCE MINIMUM TECHNICAL STANDARDS?}

This section provides a high-level overview of the various requirements that are set out in the connection network codes (CNCs). The CNCs have their basis in the network code areas 
referred to in Regulation (EC) No 714/2009. We first discuss the types of grid user and then describe the types of requirement that apply to these grid users.

\subsubsection{Different Types of Grid User}

The two CNCs we cover in this chapter are the Requirements for Generators Network Code (RfG NC) and the Demand Connection Network Code (DC NC). They refer to different types of grid user: on the one hand power-generating modules (PGMs), which include synchronous power-generating modules (SPGMs), power park modules (PPMs) and offshore power park modules (OPPMs); on the other hand transmission-connected demand facilities, transmission-connected distribution facilities, distribution systems, including closed distribution systems, and demand units which are used by a demand facility or a closed distribution system to provide demand response services to relevant system operators. The different types of grid user are explained in Annex 6A.1. Note that in this book we do not cover the third connection code, the High Voltage Direct Current Network Code (HVDC NC).

The RfG NC applies to new PGMs which are considered significant, unless otherwise provided. PGMs that are considered significant need to comply with the requirements of the RfG NC according to the voltage level of their connection point and their maximum capacity (in MW). As Table 6.1 shows, the RfG NC differentiates between four categories of PGMs (types A to D). It only sets the upper limits ('upper limit minimum capacity threshold') of the capacity thresholds used to divide the PGMs into different types, and these limits differ across the synchronous areas. The final thresholds for the different types are set at the national level and can be lower than the maximum threshold, except for type A PGMs. It is important to note that the final thresholds chosen at the national level are also strongly dependent on national practices before the entry into force of the RfG NC.

Generally, all the RfG NC requirements for lower category PGMs (e.g. PGM type A) need to be fulfilled by those in a higher category (e.g. PGM type B). Note in this context that, despite exceptions, the thresholds are generally lower in 'smaller' synchronous areas (with a lower annual net electricity generation). This means that there are relatively more PGMs in the higher classes $(\mathrm{C}$ and $\mathrm{D})$, which generally have more stringent requirements to satisfy. Furthermore, specific requirements apply to SPGMs of types B to D, PPMs of types B to D, and AC-connected OPPMs. Last, the requirements can also differ between system operators (DSOs or TSOs) when the specific requirement is to be set by the system operator that a grid user has a grid connection contract with. All the requirements are minimum requirements, which means that PGMs can always have more enhanced capabilities if this does not negatively impact system security.

The DC NC splits the different requirements into two groups: first, requirements for transmission-connected demand facilities, transmission-connected distribution facilities and distribution systems, including closed distribution systems; second, requirements for demand units used by a demand facility or a closed distribution system to provide demand response services to relevant system operators. Depending on the voltage level of the connection, the requirements can differ within these two groups. 
Table 6.1 Limits for thresholds for different types of power-generating modules

\begin{tabular}{|c|c|c|c|c|c|}
\hline Type & Threshold & & & & \\
\hline \multirow[t]{2}{*}{ A } & $\geq 0.8 \mathrm{~kW}$ & & & & \\
\hline & Continental Europe & Nordic & Great Britain & Ireland & Baltic \\
\hline B & $1 \mathrm{MW}$ & $1 \mathrm{MW}$ & $1.5 \mathrm{MW}$ & $0.1 \mathrm{MW}$ & $0.5 \mathrm{MW}$ \\
\hline $\mathrm{C}$ & $50 \mathrm{MW}$ & $50 \mathrm{MW}$ & $10 \mathrm{MW}$ & $5 \mathrm{MW}$ & $10 \mathrm{MW}$ \\
\hline $\mathrm{D}^{*}$ & $75 \mathrm{MW}$ & $75 \mathrm{MW}$ & $30 \mathrm{MW}$ & $10 \mathrm{MW}$ & $15 \mathrm{MW}$ \\
\hline
\end{tabular}

Note: $\quad *$ PGMs with a connection point $\geq 110 \mathrm{kV}$ are categorized as type D.

Source: $\quad$ RfG NC, Art. 5.

\subsubsection{Different Types of Requirement}

The technical requirements in the $\mathrm{CNCs}$ are divided into mandatory and non-mandatory requirements, each of which can be either exhaustive or non-exhaustive. Exhaustive requirements do not need further national specification, while non-exhaustive requirements need further specification at the national level for their entire application either in general or as a site-specific choice, and within the boundaries set at the regional level. In other words, non-exhaustive requirements do not provide for a full harmonization. Mandatory requirements are to be applied in all EU Member States and other countries which implement the CNCs, while for non-mandatory requirements countries can decide whether they want to introduce such a requirement either in general at the national level or as a site-specific choice. ${ }^{4}$

Most of the requirements described in the RfG $\mathrm{NC}$ and $\mathrm{DC} \mathrm{NC}$ are non-exhaustive requirements. The specification of non-exhaustive requirements at the national level may require updating and amending technical specifications, such as existing national grid codes. Therefore, a transition period from the date of entry into force of the CNCs to their application is foreseen, as is illustrated in Box 6.1.

\section{BOX 6.1 RfG NC AND DC NC TIMELINES AND NATIONAL IMPLEMENTATION PROCESSES}

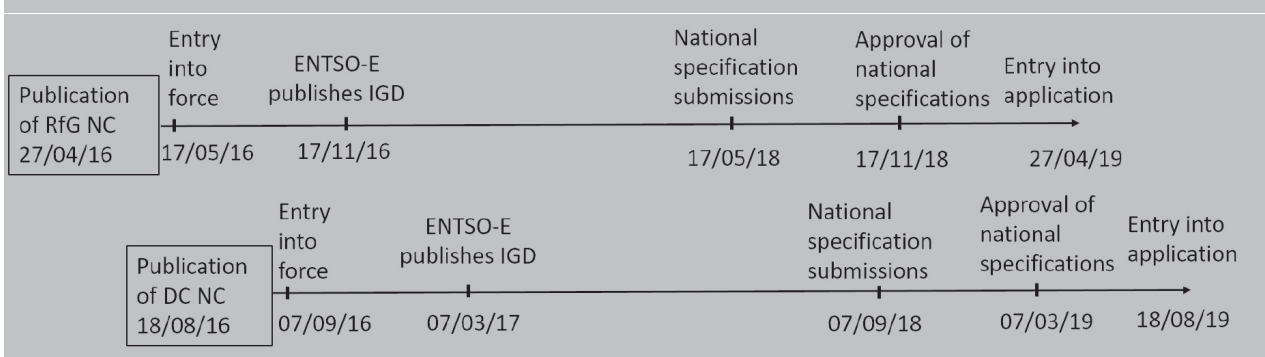

Figure 6.3 Timelines from publication to entry into application of RfG NC and DC NC

The Member States had the obligation to implement the CNCs at the national level no later than three years after they were published, as is shown in Figure 6.3. Within this timeframe, the relevant system operator, which in most cases was the TSO in coordination with the 
DSOs, had two years to define and submit a national specification of the non-exhaustive requirements for approval by the competent entity. In order to support implementation at the national level and in line with the legal requirements in the CNCs, ENTSO-E had an obligation to provide non-binding implementation guidance documents (IGDs). For reasons of transparency, ENTSO-E monitored the CNC implementation process across the Member States. Three years after the publication of the CNCs, all the parties affected had to comply with the regulations. The CNC implementation process did not end with the entry into application of the individual codes. On the contrary, all the relevant stakeholders have to continually analyse the technical details of the codes and monitor whether the requirements need to be revised in the light of system needs in future grid scenarios with increased penetration of renewable energy sources.

Below we introduce the different types of non-exhaustive requirements related to frequency issues, voltage issues, robustness, system restoration and general system management. ${ }^{5}$

First, there are three types of frequency-related requirements. The first type is related to system inertia. As was explained in Chapter 1, the inertia of a system relates to the magnitude of frequency deviations due to sudden imbalances between load and generation. If the system inertia is low, a small sudden difference between load and generation causes a high frequency deviation, and vice versa. Therefore, the RfG NC gives the relevant TSOs the right to specify that PPMs of types C and D must be capable of providing synthetic inertia during very fast frequency deviations to replace the effect of the inertia traditionally provided by SPGMs. The level of inertia influences the frequency gradient (rate of change of frequency, RoCoF) and therefore the stability of the power system. The RfG NC states that all types of PGM must be capable of staying connected to the network and operating at RoCoFs up to a value specified by the relevant TSO. In relation to this, the RfG NC and the SO GL address ramping constraints. The DC NC states that demand units offering demand response must have the withstand capability to not disconnect from the system under a RoCoF up to a value specified by the relevant TSO.

A second type of frequency-related requirement specifies certain frequency ranges within which PGMs, transmission-connected demand facilities, transmission-connected distribution facilities, distribution systems and demand units providing demand response services should be able to withstand frequency disturbances for a certain period of time without disconnecting from the grid, as is shown in Table 6.2. This is important to avoid a sudden loss of a large group of generators which could then initiate a cascading failure. The trade-off here is that if PGMs or demand facilities are exposed to over-frequency or under-frequency for too long their equipment can be damaged. Frequency ranges and duration of connection requirements are defined by synchronous area. The RfG NC foresees that the relevant system operator in coordination with the owner of the PGM may agree on wider frequency ranges, longer minimum times for operation or specific requirements for combined frequency and voltage deviations. The DC NC states that the owner of a transmission-connected demand facility or the DSO may agree with the relevant TSO on wider frequency ranges or minimum times for operation.

A third type of frequency-related requirement relates to the ability of PGMs and demand units providing demand response services to contain or compensate for a frequency drop or rise by regulating the active power output or input. This last type is related to the balancing 
Table 6.2 Frequency ranges and duration of connection requirements by synchronous area for PGMs of all types and transmission-connected demand facilities, transmission-connected distribution facilities, distribution systems and demand units providing demand response services

\begin{tabular}{|c|c|c|c|c|c|}
\hline Frequency range & $\begin{array}{l}\text { Continental } \\
\text { Europe }\end{array}$ & Nordic & Great Britain & Ireland & Baltic \\
\hline $47.0-47.5 \mathrm{~Hz}$ & - & - & $20 s$ & - & - \\
\hline $47.5-48.5 \mathrm{~Hz}$ & $\begin{array}{l}\text { Specified by each } \\
\text { TSO, >=30 min }\end{array}$ & $30 \mathrm{~min}$ & $90 \mathrm{~min}$ & $90 \mathrm{~min}$ & $\begin{array}{l}\text { Specified by each } \\
\text { TSO, }>=30 \mathrm{~min}\end{array}$ \\
\hline $48.5-49.0 \mathrm{~Hz}$ & $\begin{array}{l}\text { Specified by each } \\
\text { TSO, >=period for } \\
47.5-48.5 \mathrm{~Hz}\end{array}$ & $\begin{array}{l}\text { Specified by each } \\
\text { TSO, }>=30 \mathrm{~min}\end{array}$ & $\begin{array}{l}\text { Specified by each } \\
\text { TSO, }>=90 \mathrm{~min}\end{array}$ & $\begin{array}{l}\text { Specified by each } \\
\text { TSO, >=90 min }\end{array}$ & $\begin{array}{l}\text { Specified by each } \\
\text { TSO, >=period for } \\
47.5-48.5 \mathrm{~Hz}\end{array}$ \\
\hline $49.0-51.0 \mathrm{~Hz}$ & Unlimited & Unlimited & Unlimited & Unlimited & Unlimited \\
\hline $51.0-51.5 \mathrm{~Hz}$ & $30 \mathrm{~min}$ & $30 \mathrm{~min}$ & $90 \mathrm{~min}$ & $90 \min$ & $\begin{array}{l}\text { Specified by each } \\
\text { TSO, }>=30 \mathrm{~min}\end{array}$ \\
\hline $51.5-52.0 \mathrm{~Hz}$ & - & - & $15 \mathrm{~min}$ & - & - \\
\hline
\end{tabular}

Source: $\quad$ RfG NC, Art. 13(1.a.i); DC NC, Art. 28(2.a), Art. 29(2.a) and Annex I.

mechanism (see Chapter 5) and includes requirements for both for operation under normal conditions and for operation in emergency situations, such as operation in frequency sensitivity mode. Frequency sensitive mode is the PGM operating mode in which the active power output changes in response to a change in the system frequency so as to assist with recovery to the target frequency.

Second, there are three types of voltage-related requirements. An important difference with respect to frequency is that voltage issues have to be dealt with locally, although they can also have a cross-border impact if not dealt with properly. Frequency can be controlled by adjusting active power consumption or generation, while voltage is controlled by reactive power consumption or generation. A first type of voltage-related requirements is reactive power requirements. The DC NC specifies these for transmission-connected demand facilities and transmission-connected distribution systems. A second type specifies certain voltage ranges within which PGMs of type D, transmission-connected demand facilities, transmission-connected distribution facilities and transmission-connected distribution systems should remain connected to the grid for certain time periods. As with frequency ranges and their duration, the time period chosen for remaining connected during a voltage deviation should be long enough for the TSO to take the necessary mitigating actions and short enough to limit constraints on grid user equipment. A third type of voltage-related requirements is reactive power capabilities of PGMs of types B to D and demand units providing demand response services to contain or compensate for voltage deviations from the reference values. As with frequency, this last type covers both actions taken under normal system operation and actions taken in emergency situations.

Third, there are robustness-related requirements. Robustness or resilience can be defined as the ability to cope with disturbances without loss of proper functioning. In the context of the $\mathrm{CNCs}$, this means the ability to cope with disturbances and to help prevent any major disruption or to facilitate restoration of the system after a collapse. More specifically, generation and 
Table 6.3 Compliance of different types of power-generating modules with a selection of technical requirements as described in the RfG NC

\begin{tabular}{lllll}
\hline & Type A & Type B & Type C & Type D \\
\hline Frequency ranges & $\mathrm{x}$ & $\mathrm{x}$ & $\mathrm{x}$ & $\mathrm{x}$ \\
Fault-ride-through capability & & $\mathrm{x}$ & $\mathrm{x}$ & $\mathrm{x}$ \\
Operation in frequency sensitivity mode & & $\mathrm{x}$ & $\mathrm{x}$ \\
Voltage ranges & & & $\mathrm{x}$ \\
\hline
\end{tabular}

demand units are required to remain connected to the grid after a sudden voltage dip to help prevent any major disruption or to facilitate restoration of the system after a collapse. Voltage dips in high-voltage transmission grids are caused by switching activities which result in a redistribution of energy flows happening as a result of a short circuit or a planned disconnection. The RfG NC sets out requirements for PGMs of types B to D to remain connected to the network and operate through periods of low voltage at the connection point caused by secured faults. This is the so-called fault-ride-through capability. Moreover, SPGMs of types B to D are required to contribute to minimizing the spread of a voltage dip by recovering their active power output quickly following a voltage disturbance. Similar specifications exist for PPMs of types B to D. Relevant in this regard are also the requirements set out in the DC NC for transmission-connected demand facilities and transmission-connected distribution systems to withstand high short-circuit currents to avoid a potential cascading disconnection of grid users.

Fourth, there are system-restoration-related requirements. In Section 6.2, we introduced the system defence and restoration plans that TSOs are required to establish. It is important to have PGMs that do not need any external supply of electrical energy to restart after a blackout takes place. This is referred to as black start capability. Most PGMs do not have this capability. The RfG NC does not mandate black start capability for PGMs but refers to the right of Member States and TSOs to require owners of type C and D PGMs to equip their PGMs with a black start capability under certain conditions. Next to black start capability, the RfG NC also includes system-restoration-related requirements as regards island operation, reconnection and re-synchronization. For all three types of requirements related to system restoration, the $\mathrm{CNCs}$ set out some obligations while other requirements are to be defined by the relevant system operator.

Fifth, there are general system management related requirements. These include requirements related to information exchange with the relevant system operator, the settings of control and protection schemes, instrumentation needed to provide fault recording and monitor dynamic system behaviour and simulation models needed to test PGM compliance with the different technical requirements. These requirements can be different for different types of PGMs and for generation and demand units.

Note that the higher the classification of the PGM, the more requirements it has to satisfy, and the more stringent these requirements are, which is illustrated in Table 6.3. We will come back to this when we discuss open issues. 


\subsection{HOW TO PROCEED WITH THE IMPLEMENTATION OF TECHNICAL STANDARDS?}

In this section, we first discuss ongoing $\mathrm{CNC}$ implementation issues and then look at the case of energy storage.

\subsubsection{Implementation Issues}

Here we discuss four implementation issues regarding CNCs: the compliance by existing versus new connections, multiple connections versus a single connection, derogations at the national level and requirements versus markets.

A first open issue is compliance by new versus existing connections. The DC NC applies to new transmission-connected demand facilities, new transmission-connected distribution facilities, new distribution systems, including closed distribution systems, and new demand units used by a demand facility or a closed distribution system to provide demand response services to relevant system operators. As mentioned in Section 6.3.1, the RfG NC applies to PGMs that are new and significant. Significant means a PGM capacity larger than or equal to $0.8 \mathrm{~kW}$. PGMs and transmission-connected demand facilities, transmission-connected distribution facilities, distribution systems and demand units used to provide demand response services are considered new if the final and binding contract for the purchase of the main generating plant, demand equipment or demand unit is not finalized by two years after the entry into force of the relevant regulation. However, the RfG and the DC NC can also exceptionally apply to existing connections. A first exception is that TSOs can propose to the relevant regulatory authority to make existing PGMs, existing transmission-connected demand facilities, existing transmission-connected distribution facilities, existing distribution systems or existing demand units subject to all or some of the requirements of the relevant regulation. Such retroactive action can be done if the TSO deems that it faces significant factual changes in circumstances, such as an evolution of system requirements (including the penetration of renewable energy sources, smart grids, distributed generation or demand response), and the regulator agrees with it. A second exception is that, after notification by the system operator, the relevant regulatory authority can decide that existing PGMs of types $\mathrm{C}$ or D, existing transmission-connected demand facilities, existing transmission-connected distribution facilities, existing distribution systems or existing demand units have been modernized substantially and therefore need a revised or new connection agreement. How this will be handled at the Member State level remains to be seen.

A second open issue is multiple connections versus a single connection. As Table 6.3 shows, the classification of different types of PGMs impacts on how stringent the requirements are that the PGM has to comply with. A key question is whether a project can request multiple connections. Consider a wind park with ten $3.5 \mathrm{MW}$ wind turbines. If the project is treated as a single $35 \mathrm{MW}$ connection, it will be classified as a type C or even type D generation unit, depending on the control area. If it is treated as ten 3.5 MW connections, they will be classified as ten type B generation units. In the second scenario, the project will have to comply with less stringent requirements. The RfG NC states that classification should be based on size and the effect on the overall system. Differences exist between synchronously and non-synchronously connected generation units. For synchronous generators, the RfG NC 
states that the PGM capacity should be based on machine size and include all the components of a generating facility that normally run indivisibly. This means that one large turbine equals one generation unit. For non-synchronous generation units, the RfG NC is less clear. It states that non-synchronously connected PGMs should be assessed on their aggregated capacity where they are collected together to form an economic unit and where they have a single connection point. It all comes down to the definition of economic unit and single connection point, which is left to Member States, so how this will be handled in detail is an open issue. Note that the DC NC does not define different categories with different technical requirements, so this issue does not apply to demand connections. However, the DC NC clarifies that demand connections with more than one demand unit are to be considered as one demand unit if they cannot be operated independently from each other or can reasonably be considered in a combined manner.

A third open issue is derogations at the national level. Three aspects of derogations are worth noting. First, the criteria for granting derogations are defined by the NRAs. The European Commission may require an NRA to amend the criteria if they are not in line with the CNC. Additionally, if an NRA deems that it is necessary due to a change in circumstances relating to an evolution of system requirements, it may review and amend the criteria for granting derogations at most once a year. Second, two types of derogations exist depending on who files the request. Derogations can be requested by a PGM or demand facility owner or prospective owner. They can also be requested by a system operator for classes of PGMs or for multiple demand facilities. In such a case, the system operator would consider the need for more stringent requirements than those provided by the $\mathrm{CNC}$ to guarantee secure system operation. Third, all decisions regarding derogations granted or refused are notified to ACER and kept in a regularly updated register. ACER and the European Commission both have the possibility of issuing a reasoned recommendation to a regulatory authority to revoke a derogation due to a lack of justification. It remains to be seen to what extent derogations will be used.

A fourth open issue is requirements versus markets. Non-frequency ancillary services may follow a similar path to frequency ancillary services. As was discussed in Chapter 5, frequency ancillary services, or balancing, evolved from technical mechanisms into markets. As discussed in this chapter, non-frequency ancillary services can be treated as technical requirements in connection agreements, but they can also evolve into services that are procured in markets. In some countries, TSOs have already started to define and procure services such as black start capabilities and voltage control. The power system of the future might also require the definition of new requirements and/or services. Inertia might also become a scarce resource in larger synchronous systems as we move towards a power system with more non-synchronous generation units. Regulation (EU) 2019/943 foresees a second generation of network codes which will include rules on the non-discriminatory transparent provision of non-frequency ancillary services, including rules on voltage control, inertia, black start capability and others. To what extent these rules will lead to new requirements or markets is an open issue. ${ }^{6}$

\subsubsection{The Case of Energy Storage}

Two aspects of current discussions around energy storage are worth noting. First, with the exception of pump-storage power-generating modules, which were included in the RfG NC, the first generation of network codes does not cover energy storage. Member States are 
therefore free to follow one of three paths. They can treat storage under one of the existing asset classes of generation or demand and apply the relevant requirements of the relevant connection code; they can create a new asset class and create a separate grid code for energy storage; or they can also do something in between by starting from one of the existing codes and making a few adaptations to reflect the specificities of storage technologies.

Second, Regulation (EU) 2019/943 foresees a second generation of network codes to specify rules in relation to demand response, including rules on aggregation, energy storage and demand curtailment. We do not yet know whether these rules will be more like market guidelines alongside the existing CACM GL, FCA GL and EB GL or whether they will become grid connection network codes alongside the RfG NC, DC NC and HVDC NC.

\subsection{CONCLUSION}

In this chapter on how to organize system operation and connection requirements we have answered four questions. First, why pay attention to detailed technicalities? The technical requirements of grid connections came to the attention of the general public when we had a near-blackout experience triggered by a cruise ship in Germany. The first lesson learned was that system operation needs to be regionalized. This was indeed the start of voluntary initiatives that were later formalized in the SO GL and raised to the next level with the Clean Energy Package. The second lesson learned was that we need stricter requirements for new smaller units connected to the power system. The preparations for the first solar eclipse in a power system with significant amounts of solar power also inspired a more formal risk impact assessment process at the European level.

Second, how to organize regional system operation? TSOs remain the only system operators at the transmission level, but the roles of regional entities have been increasing with the changes from RSCIs to RSCs and RCCs. The Risk Preparedness Regulation, which was adopted as part of the Clean Energy Package, introduced a regional approach for preventing, preparing for and managing electricity crises, such as solar eclipses.

Third, how to introduce minimum technical standards? The connection network codes set out technical requirements for connecting different users and technologies to the grid. The Member States were obliged to implement the connection network codes at the national level no later than three years after their publication. Many non-exhaustive technical requirements had to be defined and tough choices had to be made. The requirements will continue to evolve with the power system.

Fourth, how to proceed with the implementation of technical standards? The new technical requirements mainly apply to new connections, unless the TSO successfully argues that the system needs a retroactive intervention. TSOs and grid users can also apply for derogations from the requirements that have been set, and grid users might try to escape some of the requirements by applying for multiple connections instead of a single bigger connection for a certain project. Requirements could also be at least partly replaced by markets remunerating grid users for the non-frequency ancillary services they provide. These are all open issues. The second generation of network codes might also play a role, especially in energy storage, which has not yet been addressed by the first generation of codes. 


\section{NOTES}

1. This account of the solar eclipse is mostly based on the impact analysis by ENTSO-E (2015) and a report by ENTSO-E and SolarPower Europe (2015).

2. The incident is discussed in detail in UCTE (2007). See also the report in German by the German national regulatory authority Bundesnetzagentur (2007). Researchers from the Ecole Centrale de Lille (FR) published a video of the event, which is available on YouTube under the title 'System Disturbance in EUROPE (2006)'.

3. The RSC task of critical grid situation management is not mandated by the network codes but was introduced by ENTSO-E $(2018,2019)$ to better tackle cold spells during winter.

4. ENTSO-E (2016a) explains the differentiation and the relationship between mandatory/ non-mandatory and exhaustive/non-exhaustive requirements in a guidance document for national implementation of the CNCs.

5. Note that we do not differentiate between mandatory and non-mandatory non-exhaustive requirements. In its guidance document, ENTSO-E (2016b) gives an overview of non-exhaustive requirements in the CNCs and specifies which parameters are mandatory and which are non-mandatory.

6. For a long time there has been a debate in academia on whether in the presence of voltage constraints reactive power prices should also be determined in addition to active power prices. For example, Hogan (1993) claims that reactive power prices complementing active power prices are needed, while Kahn and Baldick (1994) state that 'reactive power is cheap', and that reactive power pricing can be very hard in practice. Anaya and Pollitt (2018) explore the international experience of system operators procuring reactive power in different jurisdictions, including Australia, the United States and Great Britain.

\section{REFERENCES}

Anaya, K. L. and M. G. Pollitt (2018), 'Reactive power procurement: Lessons from three leading countries', Cambridge Working Papers in Economics: 1854.

Bundesnetzagentur (2007), 'Bericht der Bundesnetzagentur für Elektrizität, Gas, Telekommunikation, Post und Eisenbahnen über die Systemstörung im deutschen und europäischen Verbundsystem am 4. November 2006' ['Court of Justice of the European Communities for Electricity, Gas, Telecommunications, Post and Electricity Transmission Systems in the European Union and in the European Union on 4 November 2006'].

ENTSO-E (2015), 'Solar Eclipse 2015. Impact Analysis'.

ENTSO-E (2016a), 'Making Non-Mandatory Requirements at European Level Mandatory at National Level. ENTSO-E Guidance Document for National Implementation for Network Codes on Grid Connection'.

ENTSO-E (2016b), 'Parameters of Non-Exhaustive Requirements. ENTSO-E Guidance Document for National Implementation for Network Codes on Grid Connection'.

ENTSO-E (2018), 'Annual Report 2017'.

ENTSO-E (2019), 'Enhanced TSO Regional Coordination for Europe: Act Locally, Coordinate Regionally, Think European'.

ENTSO-E and SolarPower Europe (2015), 'Solar eclipse March 2015: The successful stress test of Europe's power grid - more ahead', Policy Brief, 15 July.

Hogan, W. W. (1993), 'Markets in real electric networks require reactive prices', Energy Journal, 14 (3), 171-200.

Kahn, E. and R. Baldick (1994), 'Reactive power is a cheap constraint', Energy Journal, 15 (4), 191-201.

Netbeheer Nederland (2019), 'DCC Compliance Verification. Transmission Connected Demand Facilities, Transmission Connected Distribution Facilities and Distribution Systems. Version 1.0. Valid from 18 August 2019'.

UCTE (2007), 'Final Report - System Disturbance on 4 November 2006'. 


\section{A.1 ANNEX: TYPES OF GRID USERS IN THE RfG AND DC NC}

\section{Types of Grid Users in the RfG NC}

The RfG NC is applicable to power-generating modules, which means either synchronous power-generating modules or power park modules. An offshore power park module is a type of power park module that is specified on the basis of its location. According to the definitions in Article 2 of the RfG NC,

- A power-generating module (PGM) means 'either a synchronous power-generating module or a power park module.'

- A synchronous power-generating module (SPGM) means 'an indivisible set of installations which can generate electrical energy such that the frequency of the generated voltage, the generator speed and the frequency of network voltage are in a constant ratio and thus in synchronism.'

- A power park module (PPM) means 'a unit or an ensemble of units generating electricity, which is either non-synchronously connected to the network or connected through power electronics, and that also has a single connection point to a transmission system, distribution system including closed distribution system or HVDC system.'

- An offshore power park module (OPPM) means 'a power park module located offshore with an offshore connection point.'

A conventional power plant falls under the definition of an SPGM. An asynchronously connected wind power plant is treated as a non-synchronously connected PPM. Solar photovoltaic or electricity storage devices connected through an inverter are treated as PPMs connected through power electronics. An AC-connected offshore wind power plant is treated as an OPPM. Note, however, that an AC-connected onshore wind power plant is treated as a PPM. Note also that an offshore wind power plant that is connected through an HVDC system is treated as a DC-connected PPM in the HVDC NC.

\section{Types of Grid Users in the DC NC}

The DC NC is applicable to what are defined in its Article 2 as

- Transmission-connected demand facilities, which means 'a demand facility which has a connection point to a transmission system', with a demand facility being defined as 'a facility which consumes electrical energy and is connected at one or more connection points to the transmission or distribution system. A distribution system and/or auxiliary supplies of a power generating module do not constitute a demand facility.'

- Transmission-connected distribution facilities, which means 'a distribution system connection or the electrical plant and equipment used at the connection to the transmission system.'

- Distribution systems, including closed distribution systems, with closed distribution systems being defined as 'a distribution system classified pursuant to Article 28 of Directive 2009/72/EC as a closed distribution system by national regulatory authorities or by other competent authorities, where so provided by the Member State, which distributes 
electricity within a geographically confined industrial, commercial or shared services site and does not supply household customers, without prejudice to incidental use by a small number of households located within the area served by the system and with employment or similar associations with the owner of the system.'

- Demand units used by a demand facility or a closed distribution system to provide demand response services to relevant system operators and relevant TSOs, with a demand unit being defined as an 'indivisible set of installations containing equipment which can be actively controlled by a demand facility owner or by a CDSO [closed distribution system operator], either individually or commonly as part of demand aggregation through a third party.' The relevant system operator is defined in the RfG NC as 'the transmission system operator or distribution system operator to whose system a power-generating module, demand facility, distribution system or HVDC system is or will be connected.'

It is important to note that the DC NC differentiates between 'system', 'facility' and 'unit'. Figure 6A.1 illustrates the use of the terms 'system' and 'facility' in the DC NC.

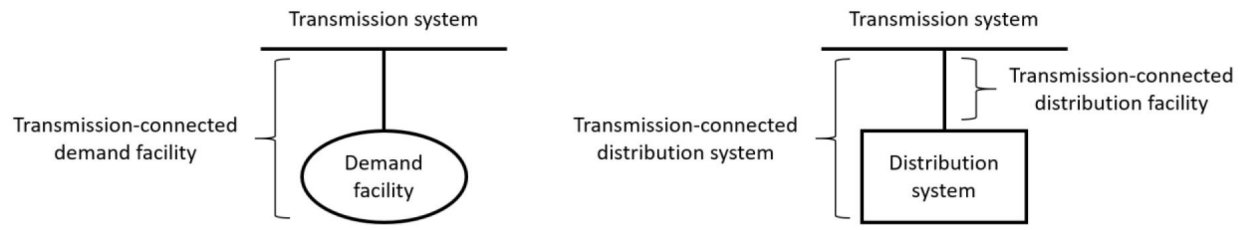

Source: $\quad$ Modified from Netbeheer Nederland (2019).

Figure 6A.1 Illustration of the terms 'demand facility', 'distribution facility' and 'distribution system' as used in the DC NC 


\section{A.2 ANNEX: REGULATORY GUIDE}

\section{Table 6A.1 Regulatory guide}

Section of this chapter, topic and relevant regulation

\section{Section 6.2}

The SO GL formalized TSO coordination by setting out common requirements for the establishment of RSCs and for their tasks.

RSCs deliver five core operational services to support national TSO decision-making.

RSCs are required to review the relevant TSO's system defence and restoration plans for consistency and to provide a technical report to all the TSOs involved.

The SO GL defines the annual reporting duties of RSCs to ENTSO-E.

RCCs are created within the geographical scope of system operation regions (SORs), a new concept introduced in the CEP.

All the TSOs in an SOR were required to forward a proposal for the establishment of RCCs for approval to the relevant NRAs by 5 July 2020.

Following approval by the NRAs, the RCCs will replace the RSCs and will enter into operation by 1 July 2022
Relevant articles

\author{
Revant articles
}

Recital 6 states that the rules set out in the SO GL require an institutional framework for enhanced coordination between TSOs, including mandatory participation of TSOs in RSCs. Furthermore, the common requirements for the establishment of RSCs and for their tasks constitute a first step towards further regional coordination and integration of system operation.

Art. 77(3) lists four tasks for RSCs: (a) regional operational security coordination; (b) building a common grid model; (c) regional outage coordination; and (d) regional adequacy assessment. A fifth task, coordinated capacity calculation, is indirectly mentioned in the CACM GL. Recital 6 of the CACM GL states that 'capacity calculation for the day-ahead and intraday should be coordinated at least at regional level.'

Art. 6 of the ER NC states that TSOs shall consult with RSCs to assess the consistency of measures defined in the system defence and restoration plans within the entire synchronous area concerned. It states furthermore that within three months of the submission of the measures by each TSO to the relevant RSC(s) the RSC(s) shall produce a technical report on the consistency of the measures based on the criteria set out in paragraph 2 of Art. 6. The report is to be transmitted without delay to all the TSOs involved, who will in turn transmit it to the relevant regulatory authorities and ENTSO-E.

Art. 17 states that 'By 1 March, each regional security coordinator shall prepare an annual report and submit it to ENTSO for Electricity', providing information on the tasks it performs.

Art. 36 of Regulation (EU) 2019/943 states that 'By 5 January 2020 the ENTSO for Electricity shall submit to ACER a proposal specifying which transmission system operators, bidding zones, bidding zone borders, capacity calculation regions and outage coordination regions are covered by each of the system operation regions.' Furthermore, the 'transmission system operators of a system operation region shall participate in the regional coordination centre established in that region.'

Art. 35 of Regulation (EU) 2019/943 states that 'By 5 July 2020, all transmission system operators of a system operation region shall submit a proposal for the establishment of regional coordination centres to the regulatory authorities concerned ...'

Art. 35 of Regulation (EU) 2019/943 states that 'Following approval by regulatory authorities of the proposal in paragraph 1, the regional coordination centres shall replace the regional security coordinators established pursuant to the system operation guideline ... and shall enter into operation by 1 July 2022.' 


\begin{tabular}{l} 
Section of this chapter, topic and relevant \\
regulation \\
\hline The CEP lists 16 tasks for RCCs. \\
RCCs shall remain open to extending their \\
portfolio to potential future needs for TSO \\
regional coordination.
\end{tabular}

RSCs issue coordinated actions to the TSOs.

ENTSO-E can delegate tasks relating to seasonal adequacy assessment and the identification of regional electricity crisis scenarios to RCCs.

On the basis of these regional electricity crisis scenarios, Member States shall establish and update their national electricity crisis scenarios, in principle every four years.

\section{Section 6.3}

The RfG NC applies to new PGMs which are considered significant, unless otherwise provided. PGMs that are considered significant need to comply with the requirements of the RfG NC according to the voltage level of their connection point and their maximum capacity (in MW).
Relevant articles

Art. 37 of Regulation (EU) 2019/943 lists the tasks for regional coordination centres, which are set out in more detail in Annex I of the same regulation.

Art. 37 of Regulation (EU) 2019/943 states that 'On the basis of a proposal by the Commission or a Member State, the Committee established by Art. 68 of Directive (EU) 2019/944 shall issue an opinion on the assignment of new advisory tasks to regional coordination centres. Where that Committee issues a favourable opinion on the assignment of new advisory tasks, the regional coordination centres shall carry out those tasks on the basis of a proposal developed by the ENTSO for Electricity and approved by ACER in accordance with the procedure set out in Art. 27.' In this respect, Art. 68 of Directive (EU) 2019/944 sets out the committee procedure, in which the 'Commission shall be assisted by a committee [composed of representatives of the Member States and chaired by a representative of the Commission] within the meaning of Regulation (EU) No 182/2011.'

Art. 42 of Regulation (EU) 2019/943 states that 'Regional coordination centres shall issue coordinated actions to the transmission system operators ...'

Art. 42 also sets out the procedures described in Subsection 6.2.1 regarding the implementation of coordinated actions issued by the RSCs.

Art. 6 of the Risk Preparedness Regulation (EU) 2019/941 states that ENTSO-E ' may delegate tasks relating to the identification of regional electricity crisis scenarios to the regional coordination centres.' Art. 9 states that ENTSO-E 'may delegate tasks relating to the [seasonal] adequacy assessments to regional coordination centres.'

Art. 7 of the Risk Preparedness Regulation (EU) 2019/941 states that national electricity crisis scenarios shall be identified on the basis of at least the risks listed in Art. 5 of the same regulation for the identification of regional electricity crisis scenarios. Furthermore, 'Member States shall update the national electricity crisis scenarios every four years, unless circumstances warrant more frequent updates.'

Art. 3 states that 'the connection requirements set out in this Regulation shall apply to new power-generating modules which are considered significant in accordance with Art. 5, unless otherwise provided.' Art. 5 states that 'The power-generating modules shall comply with the requirements on the basis of the voltage level of their connection point and their maximum capacity according to the categories set out in paragraph 2' - types A to D. 


\begin{tabular}{l} 
Section of this chapter, topic and relevant \\
regulation \\
\hline The RfG NC only sets the upper limits ('upper \\
limit minimum capacity thresholds') for the \\
capacity thresholds used to divide the PGMs \\
into different types, which differ by synchronous \\
area. The final thresholds for the different types \\
are set at the national level and can be lower \\
than the maximum threshold, except for PGMs \\
of type A.
\end{tabular}

All the RfG NC requirements for lower categories (e.g. PGM type A) need to be fulfilled by a higher category PGM (e.g. PGM type B).

Furthermore, specific requirements shall apply to SPGMs of types B to D, PPMs of types B to D and AC-connected OPPMs.

All the requirements are minimum requirements, which means that PGMs can always have more enhanced capabilities if this does not impact system security negatively.

Member States have the obligation to implement the CNCs at the national level no later than three years after their publication.

The relevant system operators have two years to define and submit national specifications for non-exhaustive requirements for approval by the competent entity.

In order to support implementation at the national level and in line with the legal requirements for the CNCs, ENTSO-E has an obligation to provide non-binding implementation guidance documents.

For reasons of transparency, ENTSO-E has been monitoring the implementation process of connection network codes across Member States. The RfG NC gives the relevant TSOs the right to specify that PPMs of types C and D shall be capable of providing synthetic inertia during very fast frequency deviations to replace the effect of inertia traditionally provided by SPGMs.
Relevant articles

Art. 5 sets out the limits for thresholds for types B, C and D power-generating modules. It states that 'Proposals for maximum capacity thresholds for types $B, C$ and D power-generating modules shall be subject to approval by the relevant regulatory authority or, where applicable, the Member State.'

This is specified in Art. 14 for type B PGMs, Art. 15 for type C PGMs and Art. 16 for type D PGMs.

Specific requirements are set out in Arts. 17 to 19 for SPGMs of types B to D, Arts. 20 to 22 for PPMs of types B to D, and Arts. 23 to 28 for AC-connected OPPMs.

Recital 2 refers to Art. 5 of Directive 2009/72/EC of the Third Package, which requires that 'Member States or, where Member States have so provided, regulatory authorities ensure, inter alia, that objective and non-discriminatory technical rules are developed which establish minimum technical design and operational requirements for the connection to the system.'

Art. 72 states that the SO GL 'shall enter into force on the twentieth day following that of its publication in the Official Journal of the European Union. Without prejudice to Arts. 4(2)(b), 7, 58, 59, 61 and Title VI, the requirements of this Regulation shall apply from three years after publication.'

Art. 7(4) of the RfG NC and Art. 6(4) of the DC NC state that 'The relevant system operator or TSO shall submit a proposal for requirements of general application, or the methodology used to calculate or establish them, for approval by the competent entity within two years of entry into force of this Regulation.'

Art. 58 of the RfG NC and Art. 56 of the DC NC state that 'No later than six months after the entry into force of this Regulation, the ENTSO for Electricity shall prepare and thereafter every two years provide non-binding written guidance to its members and other system operators concerning the elements of this Regulation requiring national decisions. The ENTSO for Electricity shall publish this guidance on its website.'

This is in accordance with Art. 59 of the RfG NC and Art. 57 of the DC NC.

Art. 21(2.a) states that 'the relevant TSO shall have the right to specify that [type C] power park modules be capable of providing synthetic inertia during very fast frequency deviations.' Art. 22 states that such requirements are also applicable to type D PPMs. 


\begin{tabular}{l} 
Section of this chapter, topic and relevant \\
regulation \\
\hline The RfG NC states that all PGM types shall be \\
capable of staying connected to the network and \\
operating at RoCoFs up to a value specified by \\
the relevant TSO.
\end{tabular}

The RfG NC and the SO GL address ramping constraints.

The DC NC states that demand units offering demand response shall have the withstand capability to not disconnect from the system due to RoCoFs up to a value specified by the relevant TSO.

The RfG NC and the DC NC set out frequency ranges within which PGMs, transmission-connected demand facilities, transmission-connected distribution facilities, distribution systems and demand units providing demand response services should be able to withstand frequency disturbances for a certain period of time without disconnecting from the grid.
Relevant articles

Art. 13(1.b) states that ' With regard to the rate of change of frequency withstand capability, a power-generating module [of type A] shall be capable of staying connected to the network and operate at rates of change of frequency up to a value specified by the relevant TSO, unless disconnection was triggered by rate-of-change-of-frequency-type loss of mains protection.' As mentioned previously, this is also applicable to PGMs of types B to D.

Art. 15(6.e) of the RfG NC states that 'the relevant system operator shall specify, in coordination with the relevant TSO, minimum and maximum limits on rates of change of active power output (ramping limits) in both an up and down direction of change of active power output for a power-generating module, taking into consideration the specific characteristics of prime mover technology.' Art. 137(4.a) of the SO GL states that all TSOs in an LFC block shall have the right to determine obligations regarding ramping periods and/ or maximum ramping rates for PGMs and/or demand units in the LFC block operational agreement.

Art. 28(2.k) states that 'Demand units with demand response active power control, demand response reactive power control, or demand response transmission constraint management shall comply with the following requirements, either individually or, where it is not part of a transmission-connected demand facility, collectively as part of demand aggregation through a third party ... (k) have the withstand capability to not disconnect from the system due to the rate-of-change-of-frequency up to a value specified by the relevant TSO.'

Art. 13(1.b) of the RfG NC specifies that a PGM of type A 'shall be capable of remaining connected to the network and operate within the frequency ranges and time periods' specified in that article by synchronous area. Art. 12 of the DC NC states that 'Transmission-connected demand facilities, transmission-connected distribution facilities and distribution systems shall be capable of remaining connected to the network and operating at the frequency ranges and time periods specified in Annex I.' Art. 29(2.a) states that demand units with demand response system frequency control shallbe able to operate across frequency ranges specified in Art. 12 'either individually or, where it is not part of a transmission-connected demand facility, collectively as part of demand aggregation through a third party.' Annex I of the DC NC includes a table with the frequency ranges and time periods specified by synchronous area. 


\begin{tabular}{l} 
Section of this chapter, topic and relevant \\
regulation \\
\hline The RfG NC foresees that the relevant system \\
operator, in coordination with the relevant TSO \\
and the owner of the PGM, may agree on wider \\
frequency ranges, longer minimum times for \\
operation or specific requirements for combined \\
frequency and voltage deviations. The DC NC \\
states that the owner of a transmission-connected \\
demand facility or the DSO may agree with \\
the relevant TSO on wider frequency ranges or \\
minimum times for operation.
\end{tabular}

A set of requirements relate to the capability of PGMs and demand units providing demand response services to contain or compensate for a frequency drop or rise by regulating the active power output or input. They include requirements both for operation under normal conditions and for operation in emergency situations.

The DC NC specifies the reactive power requirements for transmission-connected demand facilities and transmission-connected distribution systems.

The RfG NC and DC NC set out voltage ranges within which PGMs of type D, transmission-connected demand facilities, transmission-connected distribution facilities and transmission-connected distribution systems should remain connected to the grid for certain time periods.
Relevant articles

Art. 13(1.a.ii) states that 'the relevant system operator, in coordination with the relevant TSO and the power-generating facility owner may agree on wider frequency ranges, longer minimum times for operation or specific requirements for combined frequency and voltage deviations to ensure the best use of the technical capabilities of a power-generating module, if it is required to preserve or to restore system security.' Art. 12(2) of the DC NC states that 'The transmission-connected demand facility owner or the DSO may agree with the relevant TSO on wider frequency ranges or longer minimum times for operation. If wider frequency ranges or longer minimum times for operation are technically feasible, the consent of the transmission-connected demand facility owner or DSO shall not be unreasonably withheld.'

Under normal operating conditions, the relevant requirements relate to the operation of PGMs of types $\mathrm{C}$ and $\mathrm{D}$ in frequency sensitive mode as set out in Art. 15(2.d) and Art. 16(1). Art. 28(2), Art. 29(2) and Art. 30(2) of the DC NC set out provisions for demand units with demand response active power control, demand response system frequency control and demand response very fast active power control respectively.

The relevant requirements in emergency situations are related to the capability of all PGMs to run in limited frequency sensitive mode as specified in Art. 13(2) of the RfG NC. Art. 15(2.c) of the RfG NC adds specific requirements for types C and D. In addition, Art. 15(2.f) states that PGMs of types C and D which are capable of acting as a load shall be capable of disconnecting their load. Finally, Art. 19(1) of the DC NC covers demand disconnection and reconnection.

This is in accordance with the provisions in Art. 15. Art. 15(1) states that 'Transmission-connected demand facilities and transmission-connected distribution systems shall be capable of maintaining their steady-state operation at their connection point within a reactive power range specified by the relevant TSO' in accordance with conditions specified in this article.

Art. 16(2) of the RfG NC sets out requirements with regard to voltage ranges for PGMs of type D. Art. 13(1) of the DC NC states that 'Transmission-connected demand facilities, transmission-connected distribution facilities and transmission-connected distribution systems shall be capable of remaining connected to the network and operating at the voltage ranges and time periods specified in Annex II.' Annex II of the DC NC includes tables with voltage ranges and time periods specified by synchronous area. 


\begin{tabular}{l} 
Section of this chapter, topic and relevant \\
regulation \\
\hline A set of requirements relate to the reactive \\
power capabilities of PGMs of types B to D \\
and demand units providing demand response \\
services to contain or compensate for voltage \\
deviations from the reference value.
\end{tabular}

The RfG NC sets out requirements for PGMs of types B to D to remain connected to the network and operate through periods of low voltage at the connection point caused by secured faults.

SPGMs of types B to D are required to contribute to minimizing the spread of a voltage dip by quickly recovering their active power output following a voltage disturbance. Similar specifications exist for PPMs of types B to D.

The DC NC sets out requirements for transmission-connected demand facilities and transmission-connected distribution systems to withstand high short-circuit currents to avoid a potential cascading disconnection of grid users. The RfG NC does not mandate black start capability for PGMs but refers to the right of Member States and TSOs to require owners of types $\mathrm{C}$ and D PGMs to equip their PGMs with a black start capability under certain conditions. In addition to black start capability, the RfG NC also includes system-restoration-related requirements as regards island operation and reconnection and re-synchronization.
Relevant articles

Under normal operating conditions, the relevant requirements are related to the right of system operators to specify reactive power capabilities of SPGMs as set out in Art. 17(2.a) and reactive power capabilities at maximum and below maximum capacity as set out in Art. 18(2.a-c) and Art. 19(1) of the RfG NC. Art. 17(2.b), Art. 18(1) and Art. 19(2) of the RfG NC set out provisions for PGMs to be equipped with a voltage control system. Arts. 20(2.a), 21(3.a-c) and 22 set out requirements for reactive power capabilities of PPMs. Art. 21(3.d) and Art. 22 define reactive power control modes for PGMs of types C and D. Art. 28(2) of the DC NC includes provisions for demand units providing reactive power control. Art. 15(3-4) states that the relevant TSO may require a transmission-connected distribution system to actively control the exchange of reactive power at the connection point. The relevant requirements in emergency situations are related to the capability of PGMs to automatically disconnect as set out in Arts. 15(3) and 16(2.c) of the RfG NC. Art. 13(6) and Art. 19(2) of the DC NC set out requirements for the automatic disconnection of a transmission-connected demand facility, a transmission-connected distribution facility and a transmission-connected distribution system, if required by the relevant TSO. Art. 28(3) of the DC NC sets out requirements for demand units providing demand response services related to voltage control with disconnection and reconnection.

This is in accordance with Arts. 14(3), 15(1) and (4) and 16(1) and (3) for PGMs of types B to D.

Art. 17 of the RfG NC states that "type B synchronous power-generating modules shall be capable of providing post-fault active power recovery. The relevant TSO shall specify the magnitude and time for active power recovery.' Art. 18(1) and Art. 19(1) cover the applicability for SPGMs of types C and D respectively. Regarding PPMs, Art. 20(3) states that 'the relevant TSO shall specify the post-fault active power recovery that the power park module is capable of providing' and related parameters.

Art. 14 sets out short-circuit requirements. Art. 14(1) states that 'Based on the rated short-circuit withstand capability of its transmission network elements, the relevant TSO shall specify the maximum short-circuit current at the connection point that the transmission-connected demand facility or the transmission-connected distribution system shall be capable of withstanding.' Art. 15(5.a.i) states that 'black start capability is not mandatory [for type C PGMs] without prejudice to the Member State's rights to introduce obligatory rules in order to ensure system security.' Art. 16(1) refers to the applicability for type D PGMs.

Art. 15(5) and Art. 16(1) specify that PGMs of types C and D shall be capable of taking part in island operation if required by the relevant system operator in coordination with the TSO. Art. 14(4), Art. 15(1) and (5.c) and Art. 16(1) set out reconnection and re-synchronization requirements for PGMs of types $\mathrm{B}, \mathrm{C}$ and $\mathrm{D}$. 


\begin{tabular}{l} 
Section of this chapter, topic and relevant \\
regulation \\
\hline The CNCs also include requirements related to \\
general system management.
\end{tabular}

\section{Section 6.4}

The scope of application of the DC NC.

PGMs and transmission-connected demand facilities, transmission-connected distribution facilities, distribution systems and demand units used to provide demand response services are considered new if the final and binding contract for the purchase of the main generating plant, demand equipment or demand unit is not finalized by two years after the entry into force of the relevant regulation.

The RfG and the DC NC can also exceptionally apply to existing connections.

The RfG NC states that the significance of PGMs, and therefore their classification, should be based on their size and their effect on the overall system. Differences exist between synchronously and non-synchronously connected generation units.

The DC NC states that demand connections with more than one demand unit shall be considered to be one demand unit if they cannot be operated independently from each other or can reasonably be considered in a combined manner.
Relevant articles

The RfG NC specifies general system management requirements in Arts. 14(5), 15(1) and (6) and 16(1) and (4) for PGMs of types B to D and in Art. 28 for AC-connected OPPMs.

Art. 3(1) states that 'the connection requirements set out in this Regulation shall apply to: (a) new transmission-connected demand facilities; (b) new transmission-connected distribution facilities; (c) new distribution systems, including new closed distribution systems; (d) new demand units used by a demand facility or a closed distribution system to provide demand response services to relevant system operators and relevant TSOs.'

Art. 4(2) of the RfG NC specifies when a PGM shall be considered to be existing. Art. 4(2) of the DC NC specifies when a transmission-connected demand facility, a transmission-connected distribution facility, a distribution system and a demand unit that is, or can be, used by a demand facility or a closed distribution system to provide demand response services shall be considered to be existing.

Art. 4(1,3-5) of the RfG NC and Art. 4(1,3-5) of the DC NC specify the circumstances under which existing PGMs, transmission-connected demand facilities, transmission-connected distribution facilities, distribution systems and demand units that are or can be used by a demand facility or a closed distribution system to provide demand response services to a relevant system operator or relevant TSO are subject to the requirements of the respective regulation.

Recital 9 states that 'The significance of power-generating modules should be based on their size and their effect on the overall system. Synchronous machines should be classed on the machine size and include all the components of a generating facility that normally run indivisibly, such as separate alternators driven by the separate gas and steam turbines of a single combined-cycle gas turbine installation. For a facility including several such combined-cycle gas turbine installations, each should be assessed on its size, and not on the whole capacity of the facility. Non-synchronously connected power-generating units, where they are collected together to form an economic unit and where they have a single connection point, should be assessed on their aggregated capacity.'

This is specified in Art. 3(3) of the DC NC. 


Section of this chapter, topic and relevant Relevant articles
regulation

The criteria for granting derogations is defined by the NRA.

Two types of derogations exist depending on who files the request.

All decisions regarding derogations granted or refused will be notified to ACER and maintained in a regularly updated register.

ACER and the European Commission both have the possibility of issuing a reasoned recommendation to a regulatory authority to revoke a derogation due to a lack of justification.

Regulation (EU) 2019/943 foresees a second generation of network codes.

The first generation of network codes does not cover energy storage, with the exception of pump-storage power-generating modules, which were included in the RfG NC.
Art. 61(1) of the RfG NC states that 'Each regulatory authority shall specify, after consulting relevant system operators and power-generating facility owners and other stakeholders whom it deems affected by this Regulation, the criteria for granting derogations pursuant to Articles 62 and 63.' Similar provisions are specified in Art. 51 of the DC NC.

Art. 60 of the RfG NC states that 'Regulatory authorities may, at the request of a power-generating facility owner or prospective owner, relevant system operator or relevant TSO, grant power-generating facility owners or prospective owners, relevant system operators or relevant TSOs derogations from one or more provisions of this Regulation for new and existing powergenerating modules in accordance with Articles 61 to 63.' Similar powers to grant derogations are specified in Art. 50 of the DC NC.

Art. 64 of the RfG NC and Art. 54 of the DC NC state that 'Regulatory authorities shall maintain a register of all derogations they have granted or refused and shall provide the Agency with an updated and consolidated register at least once every six months, a copy of which shall be given to ENTSO for Electricity.'

Art. 65(2) of the RfG NC and Art. 54(2) of the DC NC state that 'The Agency may issue a reasoned recommendation to a regulatory authority to revoke a derogation due to a lack of justification. The Commission may issue a reasoned recommendation to a regulatory authority or relevant authority of the Member State to revoke a derogation due to a lack of justification.'

Art. 59 of Regulation (EU) 2019/943 describes the establishment of network codes. Art. 59(1) lists areas where the 'Commission is empowered to adopt implementing acts in order to ensure uniform conditions for the implementation of this Regulation by establishing network codes.' Art. 59(2) lists areas where the 'Commission is empowered to adopt delegated acts in accordance with Article 68 supplementing this Regulation with regard to the establishment of network codes.' Art. 68 refers to the power to adopt delegated acts that is conferred on the Commission.

Art. 3 states that the RfG NC shall not apply to '(d) storage devices except for pump-storage power-generating modules in accordance with Article 6(2).' Art. 6(2) refers to the application of the RfG NC and states that 'Pump-storage power-generating modules shall fulfil all the relevant requirements in both generating and pumping operation mode.' 